\title{
Lingual Raynaud phenomenon
}

\section{Alireza Fotouhi Ghiam MD MSc, John Cho MD PhD}

Competing interests: None declared.

This article has been peer reviewed.

The authors have obtained patient consent.

Affiliations: Department of Radiation Oncology (Ghiam, Cho), University of Toronto; Radiation Medicine Program (Ghiam, Cho), Princess Margaret Cancer Centre, University Health Network, Toronto, Ont.

Correspondence to: John Cho, john.cho@rmp. uhn.on.ca

CMAJ 2015. DOI:10.1503 /cmaj.140784

A Raynaud phenomenon. 45-year-old woman with squamous cell carcinoma of her right tonsil (stage $\mathrm{T} 2 \mathrm{~N} 2 \mathrm{bM} 0$ ) was given accelerated fractionated radiotherapy ( 7000 cGy in 35 fractions over $6 \mathrm{wk}$ ), concurrently with cetuximab. After completing radiotherapy, she did well for 18 months, when she had intermittent episodes of blue discoloration of her tongue (Figure 1). These self-limiting episodes happened several times a day, apparently precipitated by cold weather or drinking cold drinks. She reported no tingling, pain or numbness. The symptoms did not involve her digits. There was no history of atherosclerotic or rheumatic disease, and she was not taking any medications used to treat

The findings on physical examination were normal, aside from radiation-related fibrosis and telangiectasia involving the soft palate and right tonsil (Figure 1A). Magnetic resonance imaging

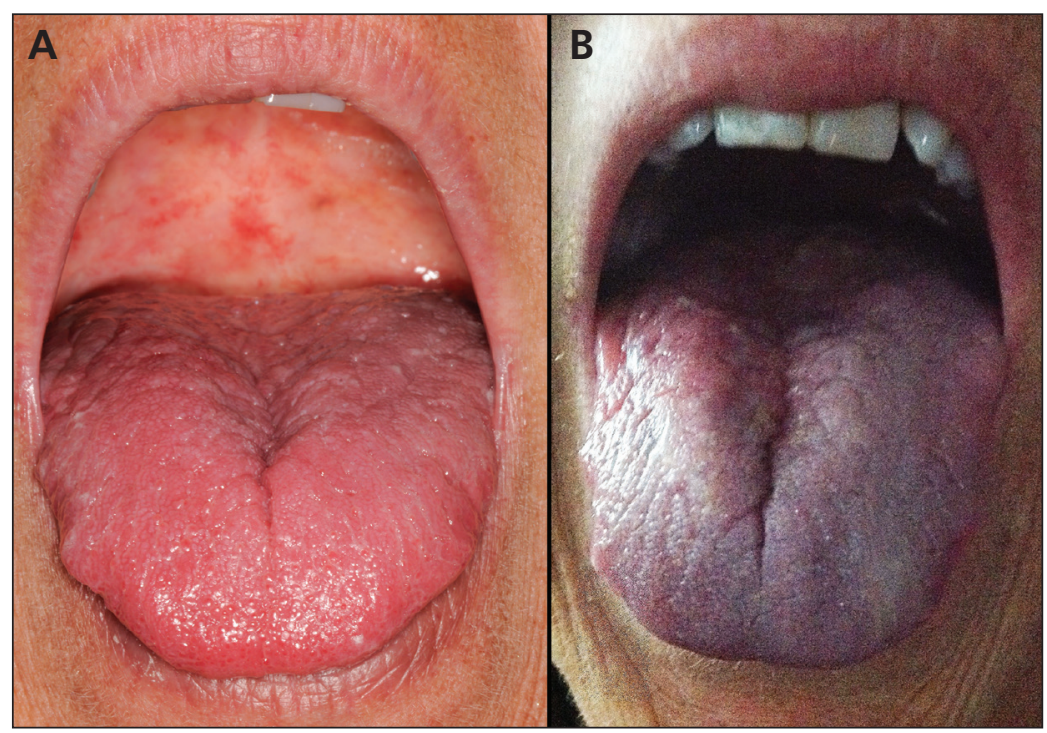

Figure 1: Blue discoloration of the tongue, predominantly on the left side, in a 45-year-old woman. The tongue changed from a normal pink colour (A) to a cyanotic purple (B), and then returned to a normal colour in a span of few minutes (see video, www.cmaj.ca/lookup/suppl/doi:10.1503/cmaj.140784/-/DC1). The photos and video are from different attacks, when the patient was exposed to cold weather. Radiation-related telangiectasia can be seen on the soft palate (A). showed postradiotherapy changes in tongue tissue; no vascular changes were identified, and sublingual arteries were normal. There was no evidence of tumour recurrence. A diagnosis of Raynaud phenomenon of the tongue was made.

Raynaud phenomenon is an exaggerated vasoconstrictive response to various stimuli, including cold temperature and emotional stress. A localized defect in arterial and arteriolar vasoconstriction is thought to underlie the disorder. ${ }^{1}$ Involvement of the tongue is rare but can occur in patients with autoimmune diseases like lupus, scleroderma and Sjögren syndrome. ${ }^{2,3}$ Lingual Raynaud phenomenon following radical radiotherapy is clinically striking but uncommon. ${ }^{4}$ No specific treatment is recommended.

Our patient continues to have intermittent, selflimiting attacks, but is otherwise well; she avoids sudden cold exposure of her tongue.

\section{References}

1. Wigley FM. Clinical practice. Raynaud's phenomenon. $N$ Engl J Med 2002;347:1001-8.

2. Cohen JC, Palomba ML, Morris LG. Raynaud's phenomenon of the tongue. J Rheumatol 2013;40:336.

3. Katada Y, Tanaka T. Images in clinical medicine. Lingual Raynaud's phenomenon. N Engl J Med 2012;366:e12.

4. Westbury CB, Harrington KJ, Rhys-Evans P, et al. Raynaud' phenomenon after radical radiotherapy for tumours of the head and neck. Postgrad Med J 2003;79:176-7.

A video showing the changes in tongue
colour is available at www.cmaj.ca/
lookup/suppl/doi:10.1503/cmaj.140784
l-/DC1.

Clinical images are chosen because they are particularly intriguing, classic or dramatic. Submissions of clear, appropriately labelled high-resolution images must be accompanied by a figure caption and the patient's written consent for publication. A brief explanation (250 words maximum) of the educational significance of the images with minimal references is required. 